\title{
LAS CLÁUSULAS ABUSIVAS Y LA CONSOLIDACIÓN DEL REMEDIO DE LA NULIDAD DE PROTECCIÓN EN EL ORDINAMIENTO JURIDICO ITALIANO*
}

\section{ABUSIVE CLAUSES AND THE CONSOLIDATION OF THE ANNULATION FOR PROTECTION REMEDY IN THE ITALIAN JURIDICAL SYSTEM}

\author{
Lorenzo Mezzasoma** \\ Fecha de recepción: 06 de noviembre de 2013 \\ Fecha de aceptación: 20 de diciembre de 2013 \\ Disponible en línea: 30 de junio de 2014
}

\section{Para citar este artículo / To cite this article}

Lorenzo Mezzasoma, Las cláusulas abusivas y la consolidación del remedio de la nulidad de protección en el ordinamiento juridico italiano, 128 Vniversitas (2014). http://dx.doi.org/10.11144/Javeriana.VJ128.cacr doi:10.11144/Javeriana.VJ128.cacr

* Resumen de la comunicación para el Tercer Congreso Euroamericano de Protección Jurídica de los Consumidores - Buenos Aires 23 al 25 de septiembre de 2010, del cual, hasta hoy, no se han publicado los actos.

** Abogado de la Università degli Studi di Perugia, con Especialización en Derecho Civil de la Università degli Studi di Camerino. Doctor en Derecho de la Universidad Autónoma de Barcelona. En la actualidad se desempeña como profesor catedrático de la Università degli Studi di Perugia. via A. Lorenzini, n. 25. Correo electrónico: lorenzo.mezzasoma@unipg.it 


\section{RESUMEN}

Las disposiciones para la protección del contratante débil han tenido un impacto enorme en el derecho civil a través de la previsión de nuevos y específicos instrumentos jurídicos desconocidos en el Código Civil italiano de 1942. Dentro de estos instrumentos cabe mencionar la importancia de la sanción especial de la nulidad relativa como medio de protección del contratante más débil. En este trabajo, tras destacar el ámbito y las características principales de esta sanción, se delinean los posibles y deseables desarrollos de las disposiciones para la protección de la parte débil.

Palabras clave: contratante débil; consumidor; autonomía contractual; invalidez; nulidad; nulidad de protección 


\section{ABSTRACT}

The rules on the protection of the weaker party have had an important and strong impact in the civil law through the implementation of new and specific juridical instruments of safeguard before unknown to the Italian Civil code. Among these, there is the peculiar sanction of the relative nullity of protection as an instrument to defend the weaker party. This paper, after highlighting the scope and the main features of this sanction, shows describes illustrates the possible and desirable developments in the provisions of the protection of the weaker party.

Keywords: weaker party; consumer; contractual autonomy; disability; nullity; nullity of protection

\section{SUMARIO}

PLANTEAMIENTO.- I. LAS CLÁUSULAS ABUSIVAS Y LA NULIDAD DE PROTECCIÓN. EL ARTÍCULO 36 DEL CODICE DEL CONSUMO ITALIANO (D.LG. DE 6 DE SEPTIEMBRE DE 2005, N. 206). UN REMEDIO PARCIAL Y RELATIVO.- II. LAS OTRAS NULIDADES REGULADAS EN EL CODICE DEL CONSUMO.- III. LOS SUPUESTOS REGULADOS EN LA LEGISLACIÓN ESPECIAL. LA MODALIDAD CONTEMPLADA EN EL D.LG. DE 22 DE JUNIO DE 2005, N. 122, EN MATERIA DE TUTELA DE LOS ADQUIRENTES DE INMUEBLES EN CONSTRUCCIÓN; LA NULIDAD DEL CONTRATO POR FALTA DE CONSTITUCIÓN DE LA GARANTÍA.- IV. LA NULIDAD EN LA CONTRATACIÓN TRAS LAS REFORMAS: HACIA UNA REGLAMENTACIÓN UNITARIA DE PROTECCIÓN DE LOS INTERESES DEL CONTRATANTE DÉBIL.- CONCLUSIÓN. 


\section{PLANTEamiento}

El objetivo del trabajo es hacer una reflexión sobre algunas importantes novedades que se han producido en el derecho civil, en particular en el derecho de consumo, con la introducción de nuevas instituciones que han cambiado las instituciones jurídicas tradicionales del ordenamiento jurídico italiano (como la nulidad, ex art. 1418 C. C.).

La metodología utilizada en el trabajo es la metodología científica que ha marcado los actuales cánones de la interpretación del derecho civil italiano, por las cual se ha pasado de una interpretación literal a una interpretación axiológica y teleológica (doctrina del Prof. P. Perlingieri).

A partir de los años ochenta son numerosos los instrumentos normativos aprobados en materia de tutela de consumidores en la Comunidad europea - en aplicación de líneas políticas de actuación que encuentran, finalmente, definitiva consagración en el Tratado de Lisboa1-, que han incidido de modo relevante sobre la disciplina del contrato, a través de la introducción de específicos principios y reglas encaminados a proteger al consumidor partiendo del presupuesto de que ocupa la posición de "contratante débil" que debe ser amparado frente al empresario, considerado, en cambio, como "contratante fuerte" 2 . Y desde esta misma perspectiva, en varios ordenamientos nacionales se ha dictado una legislación especial en la materia que, en concreto en el derecho italiano, se

1 Para un análisis de la evolución de la política comunitaria en materia de protección de consumidores puede verse L. Mezzasoma, Il consumatore acquirente di immobili da costruire fra diritto al risparmio e diritto all'abitazione, Esi, Napoli, 17 y ss. (2008); E. Capobianco en E. Capobianco y G. Perlingieri (a cura di), Codice del consumo annotato con la dottrina e la giurisprudenza, Esi, Napoli, 4 y ss. (2009).

2 En cuanto al catálogo de las intervenciones del legislador comunitario en materia contractual en protección del consumidor, v., por todos, E. Capobianco, Diritto comunitario e trasformazioni del contratto, Esi, Napoli, 13 y ss. (2003); E. Criscuolo, Diritto dei contratti e sensibilità dell'interprete, Esi, Napoli, 40 y ss. (2003); P. Perlingieri, El derecho civil en la legalidad constitucional según el sistema italo-comunitario de las fuentes, $3^{\text {a }}$ ed., Dykinson, Madrid, 485 y ss. (2008). Al mismo tiempo, no puede dejar de destacarse que también la disciplina de la responsabilidad extracontractual ha sido objeto de una significativa intervención con el fin de garantizar un elevado nivel de protección del consumidor, en particular en los casos de introducción en el mercado de productos defectuosos e inseguros, de los que viene llamado a responder el productor con base en un sistema de reglas particularmente rigurosas. Sobre estas cuestiones v. A. Cordiano, en E. Capobianco \& G. Perlingieri (a cura di), Codice del consumo annotato con la dottrina e la giurisprudenza, óp. cit., 644. 
encuentra hoy contenida, en gran parte, en el Codice del Consumo (D. Lg. 6 septiembre 2005, n. 206).

Se trata de una normativa que incide sobre la general y tradicional reglamentación del contrato prevista en el Codice Civile del 1942, realizando el tránsito de una concepción de la relación contractual fundada sobre la "igualdad formal" de los contratantes, a otra que exige la garantía de su "igualdad sustancial"'. Se configuran así "nuevos perfiles" del contrato, entre los cuales adquieren decisiva relevancia la prescripción de específicas exigencias formales, expresión del denominado "neoformalismo"; la afirmación del principio general de transparencia de las cláusulas contractuales; la atribución del derecho de desistimiento; la previsión de la sanción de

3 Con específica atención a los "contratos de consumo": V. Rizzo, Codice del consumo e definizione di clausola vessatoria, en G. Cavazzoni, L. Di Nella, L. Mezzasoma \& V. Rizzo (a cura di), Il diritto del consumo, realità e prospettive, Esi, Napoli, 121 (2008), según el cual "El aspecto fundamentalmente innovador de esta normativa respecto a la regulación tradicional consiste, como ampliamente se ha subrayado, en el hecho de que la introducción de la figura de los 'contratos de consumo', fundada en la cualidad, en el status de los contratantes, rompe uno de los principios tradicionales, el de la igualdad formal, puesto como base de aquella disciplina, y asume como elemento central y corazón de la nueva normativa un control de contenidos, también de naturaleza colectiva, que supera la perspectiva simplemente formalista y procedimental en la cual se colocan, en cambio, los arts. 1341 e 1342 C. C., encaminado a verificar la justicia y el equilibrio sustancial de la reglamentación contractual (o, al menos, a evitar la presencia de reglamentaciones que rompan abiertamente con la equidad o sean desproporcionadamente desequilibradas) operación no fácilmente conciliable con el principio de la igualdad formal". 
la nulidad "de protección"; ; todos ellos representan un compromiso significativo del dogma de la autonomía contractual ${ }^{5}$.

De ello resulta un sistema normativo que, inspirado en los principios de proporcionalidad, equidad y racionalidad, propone una reglamentación de la relación de consumo que vela por garantizar el equilibrio contractual. A tal fin, el intérprete está llamado a efectuar un control sobre el contenido del contrato ${ }^{6}$ para verificar

4 Sobre este particular, entre los numerosos estudios realizados, señalemos los siguientes: G. Passagnoli, Nullità speciali, Giuffrè, Milano (1995); G. Gioia, Nuove nullità relative e tutela del contraente debole, en Contr. impr., 1341 y ss. (1999); S. Polidori, Discipline delle nullità e interessi protetti, Esi, Napoli (2001); Id., Nullità relativa e potere di convalida, en Rass. dir. civ., 931 y ss. (2003); P. M. Putti, La nullità parziale. Diritto interno e comunitario, Esi, Napoli (2004); E. Quadri, «Nullità» e tutela del «contraente debole», en Contr. impr.,1143 y ss. (2001); A. Di Majo, La nullità, en Trattato di diritto privato diretto da M. Bessone, XXVI, Giappichelli, Torino 127 y ss. (2002); V. Scalisi, Nullità e inefficacia nel sistema europeo dei contratti, en Eur. dir. priv., 489 y ss. (2001); Id., Invalidità e inefficacia. Modalità assiologiche della negoziabilità, en I Riv. dir. civ., 201 y ss. (2003); Id., Contratto e regolamento nel piano d'azione delle nullità di protezione, I IVI, 459 y ss. (2005); Id., Il diritto europeo dei rimedi: invalidità e inefficacia, I IVI, 843 y ss. (2007); S. Monticelli, Nullità, legittimazione relativa e rilevabilità d'ufficio, en Riv. dir. priv., 685 y ss. (2002); Id., Rilevabilità d'ufficio condizionata della nullità di protezione: il nuovo Atto della Corte di Giustizia, en Contratti, 1119 y ss. (2009); P. Perlingieri, La nullità del contratto fra esigenze protettive e principio di conservazione, en Ann. Fac. econ. Bemvento, No. 9, 205 y ss. (2003); L. Ferroni, La moderna concezione costituzionale e comunitaria di autonomia negoziale e la nuova filosofia cui si informa il regime delle invalidità, en Id., Saggi di diritto civile, Esa, Pesaro-Urbino, 17 y ss. (2003); C. Caccavale, La nullità di protezione delle clausole abusive e l'art. 28 della legge notarile, en Notariato, 49 y ss. (2007); S. Polidori, Nullità relativa e limiti alla disponibilità mediante convalida della tutela apprestata in favore del consumatore dal codice di settore, en G. Cavazzoni, L. Di Nella, L. Mezzasoma y V. Rizzo (a cura di), Il diritto del consumi, realtà e prospettive, óp. cit., 212 y ss.; S. Pagliantini, Autonomia privata e divieto di convalida del contratto nullo, Torino, 151 y ss., 214 y ss. (2007); Id., La nullità di protezione tra rilevabilità d'ufficio e convalida, en 1 Persona e Mercato, 20 y ss. (2009); G. D'Amico, Nullità virtuale. Nullità di protezione (variazioni sulla nullità), en Contratti, 432 y ss. (2009); Id., Diritto europeo dei contratti (del consumatore) e nullità virtuale (di protezione), en Contratti, 977 y ss. (2012); G. Perlingieri, La convalida delle nullità di protezione e la sanatoria dei negozi giuridici, $2^{\mathrm{a}}$ ed., Esi, Napoli (2011); Id., Sanatoria e responsabilità del notaio ex art. 28, l. 16 febbraio 1913, n. 89, en Corti umbre, 15 y ss. (2013); A.Gentili, La «nullità di protezione», en Eur. dir. priv., spec. 77 y ss. (2011); G. Passagnoli, Note critiche in tema di sanabilità e rinunziabilità delle nullità di protezione, en 1 Persona e Mercato, 24 y ss. (2012); I. Prisco, La nullità di protezione: indisponibilità dell' interesse e adeguatezza del rimedio, Esi, Napoli, 86 y ss. (2012); C. Mignone, La disponibilità dell'azione di nullità nel sistema italo-comunitario delle patologie negoziali, en Corti umbre, 344 y ss. (2013).

5 P. Perlingieri, Nuovi profili del contratto, en Rass. dir. civ., 545 y ss. (2000); Id., "II diritto dei contratto fra persona e mercato. Problemi di diritto civile”, Esi, Napoli, 417 y ss. (2003); Id., El derecho civil en la legalidad constitucional según el sistema italo-comunitario de las fuentes, óp. cit., 299 y ss.

6 Ha de hacerse referencia, en particular, al art. 1469 quater C. C., ahora art. 35 del Codice del Consumo, sobre los cuales puede verse, por todos, V. Rizzo, Trasparenza e "contratti del consumatore. La novella al codice civile, rist., Esi, Napoli, 17 y ss. (2002), quien, con relación a la consolidación del principio de transparencia en la normativa de consumo, subraya que: "con el fin de aclarar el papel asignado a este principio en la economía de la nueva normativa ha de destacarse que ésta, con un efecto de ruptura respecto del pasado, invoca con claridad, siguiendo la línea marcada por el legislador comunitario, la vía del control de contenidos (y de 
si realmente, en el caso concreto, son identificables situaciones de desventaja para la parte débil ${ }^{7}$.

\section{LAS CLÁUSULAS ABUSIVAS Y LA NULIDAD DE PROTECCIÓN. EL ARTÍCULO 36 DEL CODICE DEL CONSUMO ITALIANO (D. LG. DE 6 DE SEPTIEMBRE DE 2005, N. 206). UN REMEDIO PARCIAL Y RELATIVO}

Este planteamiento encuentra una significativa manifestación en la disciplina de las cláusulas abusivas ${ }^{8}$ prevista en los arts. 33-37 bis C. Cons. Tales disposiciones reproducen esencialmente el contenido de los arts. 1469-bis - 1469-sexies Codice Civile (incorporados al Codice Civile por la Ley de 6 de febrero de 1996, n. 56, de trasposición de la Directiva Comunitaria n. 13 del 1993), y dibujan tres niveles de tutela para el consumidor, disponiendo: un concepto general de las cláusulas abusivas - definidas como aquellas que "en contra de las exigencias de la buena fe, determinan a cargo del consumidor un significativo desequilibrio de los derechos y obligaciones que derivan del contrato" (art. 33.1 C. Cons.) - ; una "lista gris" de cláusulas "que se presumen abusivas salvo prueba en contrario" respecto de las cuales, sin embargo, el empresario puede probar que fueron objeto

la justicia sustancial) de la reglamentación contractual, superando la simple fase del control en el procedimiento de formación del contrato, quebrantando bases profundamente establecidas, especialmente por parte de la jurisprudencia, y dando, en definitiva, cuerpo a las voces que insistentemente se levantaban en esta dirección en la literatura jurídica italiana, que permanecian hasta hoy confinadas en la dimensión del simple debate teórico. Y esta elección asume tanto más significado en cuanto que se opera con un corpus de normas incorporadas al Codice Civile; esto pone de manifiesto, con particular fuerza, que la perspectiva que deriva de los arts. 1341 e 1342 $C$ c, está considerada, en el sector normativo de los contratos de consumo, del todo inadecuada e insuficiente".

7 V. Rizzo, "Trasparenza”, óp. cit., 42 y ss.; Id., Art. 33, comma 1, en E. Cesáro, I contratti del consumatore, Commentario al Codice del consumo (D. Igs. 6 setiembre 2005 n. 206), Cedam, Padova, 62 y ss. (2007).

8 Para la evolución de la disciplina en materia de cláusolas abusivas en el ordinamiento juridico italiano, v. V. Rizzo, La disciplina delle clausole vessatorie: profili storici, en A. Bellelli, L. Mezzasoma y F. Rizzo (a cura di), Le clausole vessatorie a vent'anni dalla direttiva CEE 93/13, Esi, Napoli, 39 y ss. (2013); y P. Sirena, La disciplina delle clausole vessatorie nei contratti con i consumatori vent'anni dopo: bilanci e prospettive del diritto europeo dei contratti, ivi, 59 y ss.; en el ordinamiento juridico español, v. E. Llamas Pombo, Ordinamento spagnolo e clausole vessatorie, IVI, 89 y ss. El volumen citado recoge los actos de la Jornadas de Estudio "Le clausole vessatorie a vent'anni dalla direttiva CEE 93/13”, organizada por el Centro di Studi Giuridici sui diritti dei consumatori, Polo Scientifico Didattico di Terni-Università degli Studi di Perugia, Terni, 23 de mayo de 2013. 
de negociación individual (art. 33. 2 C. Cons.); y una "lista negra" de cláusulas que se consideran, en todo caso, abusivas "aunque hayan sido objeto de negociación" (art. 36.2 C. Cons.).

Para todos estos casos el Codice del Consumo establece que la sanción en caso de abusividad de la cláusula es la "nulidad de protección", regulada en el artículo 36 C. Cons., el cual, resolviendo el debate sobre la ineficacia de las cláusulas abusivas ${ }^{9}$, configura este instituto como un instrumento de tutela tanto del mercado como del contratante débil ${ }^{10}$.

Se trata de una forma de nulidad "nueva"11, que representa una evolución de la figura tradicional de nulidad, respecto de la cual transforma su esencia; de instrumento "demolitorio" que opera cuando se aprecie una carencia estructural del acto, ahora deviene mecanismo de garantía del efectivo reequilibrio - normativo y económico - del contrato y, por tanto, está llamada a desarrollar funciones constructivas y conformadoras de la reglamentación contractual ${ }^{12}$.

Así se consigue, primeramente, por un lado la superación del modelo clásico de la nulidad y, por otro que se diluya la tradicional contraposición entre nulidad y anulabilidad, pudiéndose destacar que en la disciplina de la nulidad de protección son fácilmente identificables esquemas propios del estatuto de la anulabilidad ${ }^{13}$.

9 Sobre el debate acerca de la calificación en términos de "ineficacia" de la sanción de la abusividad véase A. Orestano, L'ineficacia delle clausole vessatorie: "contratti del consumatore" e condizioni generali, Riv. Crit. Dir. Priv., 501 y ss. (1996); M. Nuzzo, Art. 1469 quinqués. Ineficacia, Nuove leggi civ. comm., 1217 y ss. (1997); F. Guaraccino, Inefficacia e nullità delle clausole vessatorie, Contr. impr./Eur., 618 y ss. (1997); R. Quadri, "Nullità" e tutela del "contraente debole"”," óp. cit., 1161 y ss.; L. Valle, "L'inefficacia delle clausole vessatorie e le nullità a tutela della parte debole del contratto", en Contr. impr., 149 y ss. (2005); Id., "L'inefficacia delle clausole vessatorie e il codice del consumo", IVI, 662 y ss. (2006); E. Graziuso, "La tutela del consumatore contro le clausole abusive", Giuffrè, Milano, 291 y ss. (2010).

10 Así se lee en la Exposición de Motivos del Codice del Consumo, § 6.

11 En la doctrina muchas veces se ha destacado el tránsito del concepto de nulidad, en singular, al carácter plural de la nulidad (por todos, V. Scalisi, "Nullitá e ineficacia nel sistema europeo dei contratti", óp. cit., 503 y ss.), a pesar de la dificultad de construir "la 'nulidad de protección' como una categoría unitaria, como si la multitud de ocasiones en que se utiliza la nulidad negocial para regular y reequilibrar el mercado de bienes y servicios estuviese constantemente sujeta a la tutela del mismo sujeto, individualizado con la etiqueta de 'contratante débil', que se persiguiera a través de recursos siempre iguales”. S. Polidori, Discipline delle nullitá e interessi protetti, óp. cit., 113.

12 V. Scalisi, Nullitá e ineficacia nel sistema europeo dei contratti, óp. cit., 499, para el cual la nulidad de protección "está en una relación directa e inmediata de congruencia y correspondencia con un determinado orden de intereses, en razón a la naturaleza de los mismos, la específica posición de las partes, los bienes y los servicios negociales".

13 P. Perlingieri, Nuovi profili del contratto, óp. cit., 570, según el cual "el concepto de invalidez 
Esto se debe al hecho de que concurre en concreto un interés de naturaleza individual ${ }^{14}$, el de garantizar un elevado nivel de protección al consumidor ${ }^{15}$, que convierte en inadecuada la disciplina tradicionalmente adscrita a la nulidad e impone la introducción de remedios sancionadores, que, al mismo tiempo, satisfagan exigencias de conservación y reequilibrio de la relación contractual ${ }^{16}$.

De hecho, pueden existir hipótesis en las que, tenidas en cuenta las circunstancias concretas, el interés del contratante débil al que se pretende tutelar no sea el de la ineficacia integral del contrato o de cláusulas singulares, sino, sin embargo, el de conservación de sus efectos ${ }^{17}$. Desde esta perspectiva, se impone una evidente desviación de las reglas del Codice Civile y se dibuja un sistema en el cual el contrato que incurre en una de las causas de nulidad puede, de todos modos, considerarse idóneo para producir los efectos que le son propios $^{18}$, incluso los traslativos: permanece válido en cuanto a las partes no ineficaces (art. 36.1 C. Cons.) ${ }^{19}$.

adquiere una flexibilidad destinada a trastocar los rígidos esquemas de clasificación, típicos de la más consolidada dogmática, acercándose, por un lado, también en la terminología, a la eliminación de la distinción entre nulidad y anulabilidad y, por otro, mostrándose disponible en la recepción de las directivas comunitarias, para acoger las formas de ineficacia en sus posibles nuevas acepciones respecto al uso tradicional".

14 En el plano doctrinal se ha señalado que el interés en cuestión está a caballo entre lo público y lo privado. Por una parte, se trata de un interés público, pues está destinado a regular el mercado según las determinaciones del derecho comunitario, en función de los principios de concurrencia, transparencia y lealtad en las relaciones comerciales. Pero el interés en cuestión tiene también relevancia individual, al estar en juego la protección de sujetos que se encuentran en una posición de inferioridad y, por ello, en riesgo de sufrir la imposición de las condiciones dictadas por la contraparte que parece ser la que determinará las reglas de la relación. La composición de estos dos intereses explica la decisión de legislador de recurrir a la nulidad y no a la anulabilidad que es, en cambio, el instrumento utilizado en la tutela de los intereses privados (sobre esta cuestión véase, ampliamente, S. Polidori, o.u.c., 11 y ss.).

15 Para L. Ferroni, o.c., p. 20: "Esta coincidencia del interés público con el interés privado explica y justifica el recurso legislativo a la nulidad (con las desviaciones destacadas respecto a la disciplina tradicionalmente ligada a ésta) para la protección inmediata y directa (también) del interés privado".

16 Según S. Polidori, o.u.c., 307, "no es la disciplina de la nulidad, en otras palabras, la que postula la conversión, la confirmabilidad, la conservación del contrato depurado de la cláusula reprobada, la eventual responsabilidad precontractual, la eficacia interina (de modo que, en donde tales figuras no sean aplicables, no podría tratarse de nulidad, sino de inexistencia) sino el interés concretamente tutelado que es sometido a juicio del intérprete".

17 P. Perlingieri, "II diritto civile nella legalitá costituzionale", óp. cit., 351 y ss., para el cual "los 'remedios' deben ser adecuados a los intereses, de manera que la prevalencia del la nulidad parcial, como expresión de la prevalencia del principio de la conservación de los efectos, es defendible siempre que sea querido (por el ordenamiento) que el contratante (débil) alcance el resultado, al menos en parte".

18 Sobre la eficacia del contrato afectado de nulidad relativa, D. Valentino, "Obblighi di informazione, contenuto e forma negoziale", Esi, Napoli, 265 (1999).

19 E. Di Marzio, "Codice del consumo, nullità di protezione e contratti del consumatore", Riv. dir. 
Característica fundamental de la nulidad que sanciona la abusividad de las cláusulas es, por tanto, la parcialidad del remedio; como resulta también en la Propuesta de Directiva del Parlamento y del Consejo sobre derechos de los consumidores de 8 de octubre de $2008^{20}$, que regula una disciplina única para los aspectos comunes a las diferentes normativas en materia de protección de consumidores $^{21}$; con referencia específica a la disciplina de las cláusulas abusivas, ha previsto en el artículo 37 de la Propuesta (bajo la rúbrica "Efectos de las cláusulas contractuales abusivas") que "las cláusulas contractuales abusivas no son vinculantes para el consumidor" y que "el contrato continúa siendo vinculante para las partes si puede permanecer en vigor sin las cláusulas abusivas”. Hay

priv., 844 (2005); Id., "La nullità del contratto", Cedam, Padova, 833 y ss. (2008).

20 Сом (2008) 614 def. Se trata de una normativa que se ha elaborado a la luz de los resultados obtenidos como consecuencia del debate desarrollado por la comunidad científica en el "Libro verde" de "revisión del acquis relativo a los consumidores", presentado el 18 de febrero de 2007 - СОм (2006) 744 def.- ha tenido como objeto ocho directivas emanadas en esta materia (la n. 577 del 1985, sobre contratos celebrados fuera de establecimientos mercantiles; la n. 314 del 1990, sobre viajes combinados; la n. 13 del 1993, sobre cláusulas abusivas; la n. 47 del 1994, sobre multipropiedad o aprovechamiento por turnos de bienes inmuebles, la n. 7 del 1997 sobre contratos a distancia; la n. 6 del 1998, sobre indicación de los precios de los productos ofertados a los consumidores; la n. 27 del 1998, sobre acciones de cesación en materia de protección de los intereses de los consumidores; la n. 44 del 1999, sobre algunos aspectos de la venta de bienes de consumo y las garantías correspondientes). La intención que se persigue con el trabajo de revisión llevado a cabo en 2007 es alcanzar un "justo equilibrio entre un elevado nivel de protección de los consumidores y la competitividad de las empresas” y, a tal fin, las principales cuestiones individualizadas por la Comisión son: la necesidad de adecuar la disciplina existente a las "nuevas exigencias del mercado", teniendo en cuenta en particular los problemas derivados del desarrollo creciente de la tecnología digital y de los servicios digitales; la "fragmentación de las reglas" y la "diversidad" de las normativas nacionales de recepción de las directivas europeas. En este contexto, la Comisión llevó a cabo una consulta pública (que terminó el 15 de mayo de 2007) en la cual, más específicamente, se analizaron las cuestiones siguientes: el concepto de consumidor y empresario; la calificación del contrato concertado por un consumidor por medio de un intermediario; la imposición de una obligación general al empresario de actuar conforme a los principios de buena fe y del comercio leal; el campo de aplicación de las normas comunitarias en materia de cláusulas abusivas; las informaciones debidas al consumidor; el derecho de desistimiento; los remedios contractuales generales; el derecho general al resarcimiento de los daños; las normas específicas aplicables a la venta de bienes de consumo (sobre el particular, véanse las respuestas a las cuestiones planteadas en el "Libro verde" de 8 de febrero de 2007 elaboradas por el grupo S.I.S.D.I.C. — compuesto por los Profesores E. Capobianco, E. Minervini, V. Rizzo, L. Mezzasoma, L. Di Nella, L. Rossi Carleo, M.C. De Cicco y L. Ruggeri-, que puede consultarse en www.sisdic.it). Todos estos aspectos confluyen después en la Propuesta de Directiva del Parlamento y del Consejo sobre derechos de los consumidores de 8 de octubre de 2008, que limita su ámbito de aplicación a cuatro directivas (la n. 577 del 1985, la n. 13 del 1993, la n. 7 del 1997 y la n. 44 del 1999).

21 El camino escogido es el de la armonización completa como resulta de la expresa previsión según la cual "Los Estados miembros no podrán mantener o introducir en su legislación nacional disposiciones contrarias a las fijadas en la presente Directiva, en particular disposiciones más o menos estrictas para garantizar un diferente nivel de protección de los consumidores" (art. 4 de la Propuesta y, hoy, art. 4 de la Directiva 2011/83/UE). 
que señalar que la propuesta de directiva ha sido hoy traspuesta en la Directiva 2011/83/UE que ha modificado las directivas mencionadas y que se ha recibido en Italia con el Decreto Legistativo del 3 de diciembre de 2013 (en vigor desde el 13 de junio de 2014). Sobre el tema de las cláusulas abusivas la Directiva 2011/83/CE, no modifica nada en relación a las sanciones aplicables, pero permite a los Estados miembros ampliar el juicio de abusividad también a las cláusulas que tratan del precio y de las remuneraciones.

Por otra parte, bajo el punto de vista de la legitimación para ejercitar la acción se pone de manifiesto la decadencia del carácter de "absoluta" de la nulidad, que cambia por su "relatividad". La acción planteada para la declaración de nulidad puede ser ejercitada exclusivamente por el consumidor y su apreciación de oficio solo se admite en los casos en que opere en "beneficio del consumidor" (art. 36.3 C. Cons.) $)^{22}$.

Viene así resuelta en sentido positivo la cuestión conflictiva relativa a la compatibilidad o no del reconocimiento de una legitimación restringida en el ejercicio de la acción y la posibilidad de que el juez aprecie la nulidad del contrato ${ }^{23}$. Y a propósito de eso hay quien ha afirmado que si se privase al juez de tal posibilidad se correría el riesgo de confundir nulidad relativa y anulabilidad ${ }^{24}$; en todo caso, tal posibilidad debe siempre entenderse limitada a los supuestos en que la parte legitimada para ejercitar la acción permanezca pasiva y la intervención del juez corresponda a un interés del consumidor ${ }^{25}$.

22 Sobre este punto, véase P. Perlingieri, o.u.c., 352, para el cual "Es erróneo, por tanto, sostener todavía hoy que la nulidad es, como regla, absoluta. Se pasa por alto, de hecho, que aquélla se ha convertido en nulidad de protección, de garantía; de manera que, 'cualquiera que tenga interés' está legitimado para hacer valer la nulidad, pero sólo el que está protegido por la nulidad".

23 Para un amplio y detallado estudio de la cuestión se reenvía a: S. Polidori, Discipline delle nullitá e interessi protetti, óp. cit., 73 y ss.

24 Así, expresamente, A. Albanese, Violazione di norme imperative e nullità del contratto, Jovene, Napoli, 63 y ss. (2003)

25 S. Polidori, Nullitá relativa e limiti di disponibilitá mediante convalida della tutela apprestata in favore del consumatore dal codice di settore, óp. cit., 215, nota 10, para el cual “la apreciación de oficio de la nulidad relativa no implica la arbitraria superposición de la valoración del juez a aquella, conscientemente discrepante, realizada por el sujeto legitimado, sino que está prevista en función de una mejor protección del interés del contratante que acaso pueda no haber advertido la posibilidad de plantear la acción. La ampliación de los poderes del juzgador responde así a la necesidad de actuar frente a un estado de debilidad que del terreno sustancial pueda proyectarse sobre el procesal, donde no siempre la parte débil puede permitirse una defensa técnica a la altura de la situación". 
En otros términos, la nulidad, precisamente porque es de protección, teniendo en cuenta las circunstancias concretas, viene a configurarse como un instrumento que, de la manera menos invasiva posible, está llamado a perseguir una tutela real del consumidor. Y desde esta perspectiva se afronta también la cuestión de la posibilidad de convalidar un contrato afectado de nulidad relativa. A la tradicional orientación contraria a tal posibilidad ${ }^{26}$, se han contrapuesto aquellas opiniones que, si bien no con carácter general, introducen soluciones diferenciadas en base a las cuales todas las veces que no resulte "concretamente denegado el interés protegido por la norma" no parece que pueda encontrar "espacio la lógica que impide la recuperación mediante convalidación de los contratos sin equilibrio, según expresa el art. 1451 Codice Civile, y ello es extensible a las hipótesis de nulidad relativa que tengan su causa en el desequilibrio de las condiciones" ${ }^{27}$.

Hay que señalar que hoy a la sanción de la nulidad se añade también la tutela administrativa introducida por el artículo 5 del d.1. 24 gennaio 2012, n. 1 (1. 24 marzo 2012, n. 27). Por medio de esta ley se reforma el Código del consumo con la introducción del art. 37 bis que faculta a la Autorità Garante per la Concorrenza de il Mercato para imponer sanciones a los profesionales que utilizan cláusulas abusivas ${ }^{28}$.

26 V., por todos, A. Gentili, "Le invalidità", en I contratti in generale a cura di E. Gabrielli, II, Trattato dei contratti diretto da Rescigno P., Utet, Torino, 1373 (1999); E. Greco, "Profili del contratto del consumatore", Jovene, Napoli, 226 y ss. (2005)

27 S. Polidori, "Nullità relativa e limiti di disponibilità mediante convalida della tutela apprestata in favore del consumatore dal codice di settore", óp. cit., 235, que se refiere, específicamente, a las hipótesis de violación del deber de información del art. $52.3 \mathrm{C}$. Cons. El autor llega a tal conclusión a través de un proceso reconstructivo que pone en evidencia cómo se ha superado en algunas disposiciones la imposibilidad de convalidación del contrato nulo, a la luz del papel sistemático atribuido al art. 1451 C.C. La solución expuesta emergía ya claramente en escritos anteriores de este mismo autor: S. Polidori, Nullitá relativa e potere di convalida, en Rass. dir. civ., 946 y ss., spec. 951 (2003). En el mismo sentido, V. Scalisi, Nullitá e ineficacia nel sistema europeo dei contratti, óp. cit., 502 y ss., quien matiza que tal posibilidad de convalidación parece admisible salvo en los casos de "irrenunciabilidad de los derechos expresamente previstos".

28 Sobre este punto, v. G. Palliggiano, "Introdotta la "patente di legalità» per le imprese", en Gli speciali di Guida al diritto, n. 16, p. XXII (2012); Id., "Vessatorietà delle clausole accertata dal garante", en Guida dir., n. 7, 44 y ss. (2012); E. Minervini, La tutela amministrativa contro le clausole vessatorie nei contratti del consumatore, en Nuove leggi civ. comm., 563 y ss. (2012); Id., "L'azione inibitoria delle clausole vessatorie", en A. Bellelli, L. Mezzasoma, y F. Rizzo, (a cura di), "Le clausole vessatorie a vent'anni dalla direttiva CEE 93/13", Esi, Napoli, 113 (2013); E. Battelli, "Il controllo amministrativo delle clausole inique", en Eur. dir. priv., 1093 y ss. (2012); V. Pandolfini, "La tutela amministrativa dei consumatori e le clausole vessatorie", en Corr. giur., 47 y ss. (2012); L. Rossi Carleo, "La tutela amministrativa contro le clausole vessatorie", en Obbl. contr., 492 y ss. (2012); T. Rumi, "Il controllo amministrativo delle clausole vessatorie", 


\section{LAS OTRAS NULIDADES REGULADAS EN EL CODICE DEL CONSUMO}

Desde un punto de vista más general, no podemos dejar de tomar en consideración cómo estos elementos propios de la nulidad de protección, que pueden deducirse del artículo 36 del Codice del Consumo, están también presentes en otras modalidades de nulidad contempladas en el mismo texto legal. Así en el artículo 134.1 C. Cons., sobre la venta de bienes de consumo, donde expresamente se prevé que la nulidad de determinadas cláusulas "solo se puede hacer valer por el consumidor y ser declarada de oficio por el juez"; en el artículo 67 - septies-decies C. Cons., en el tema de las contrataciones a distancia de servicios financieros por el consumidor, el cual dispone que la nulidad del contrato por alguna grave violación por parte del proveedor (ad ex., impedimentos para ejercer el derecho de desistimiento) "solo se puede hacer valer por el consumidor"; y además, en el artículo 67- opties-decies, que decreta la imposibilidad por parte del consumidor de renunciar a los derechos reconocidos en la sección IV bis del C. Cons., sanciona la nulidad de dichos pactos, que "solo se puede hacer valer por el consumidor y ser declarada de oficio por el juez". También donde falta una específica explicación de las características de la nulidad aplicada (como, ad ex., en el artículo 78 C. Cons., donde el legislador se limita a establecer que "son nulas las cláusulas contractuales o los pactos añadidos de renuncia del adquirente a los derechos previstos en la ley o a las limitaciones de la responsabilidad contempladas a cargo del vendedor") razones de coherencia sistemática imponen, en efecto, la superación de la relación regla y excepción aplicada a la nulidad absoluta y la relativa, llegando a considerar toda nulidad de protección como relativa. Todo esto prescindiendo del hecho de que se haya precisado explícitamente que la nulidad pueda ser instada solo por el consumidor; que aquella pueda ser apreciada

en Contratti, 638 y ss. (2012); D. Bonaccorsi di Patti, "Prime considerazioni sui procedimenti in materia di clausole vessatorie innanzi all'Autorità garante della Concorrenza e del Mercato", en Dir. fisc. ass., 35 ss. (2013); A. Querci, "Le novità introdotte nel Codice del consumo dal d.l. 1/2012 ed il ruolo delle associazioni dei consumatori nella tutela contro le clausole vessatorie", en Contr. impr., 446 ss. (2013); S. Mezzacapo, Illiceità delle clausole "abusive" (tra presidi di "giustizia negoziale" e tutela amministrativa del "mercato"), en F. Capriglione, (cur.), I contratti dei risparmiatori, Giuffré, Milano, 142 y ss. (2013). 
de oficio por el juez; y que el contrato siga siendo válido en cuanto a las partes no ineficaces. En este sentido se interpretan: el artículo 52.3 C. Cons., sobre los contratos a distancia; los artículos 71 y 76.3 C. Cons., por lo que respecta a la multipropiedad; el artículo 124 C. Cons., sobre las cláusulas de exoneración de la responsabilidad de productores; y los artículos 44.3 y 45.2 del Codice del turismo. Además, juega un papel especialmente importante el artículo 143 del Codice del Consumo que, como norma de cierre ${ }^{29}$, sanciona la imposibilidad de renunciar a los derechos atribuidos al consumidor, con la consiguiente nulidad de las estipulaciones contrarias al mismo Codice ${ }^{30}$.

\section{LOS SUPUESTOS REGULADOS EN LA LEGISLACIÓN ESPECIAL. LA MODALIDAD CONTEMPLADA EN EL D. LG. DE 22 DE JUNIO DE 2005, N. 122, EN MATERIA DE TUTELA DE LOS ADQUIRENTES DE INMUEBLES EN CONSTRUCCIÓN; LA NULIDAD DEL CONTRATO POR FALTA DE CONSTITUCIÓN DE LA GARANTÍa}

En este marco, no se puede olvidar que también al margen del Codice están reguladas algunas particulares figuras que pueden reconducirse al paradigma de la nulidad de la protección ${ }^{31}$. Entre

29 S. Polidori, Nullitá relativa e limiti di disponibilitá mediante convalida della tutela apprestata in favore del consumatore dal codice di settore, óp. cit., 217, para el cual la introducción de una norma de cierre de alcance general atribuye a la inderogabilidad el rango del principio fundamental, esencial para garantizar la efectividad de la tutela: en este sentido se justifica la idea de una absoluta indispensabilidad del interés protegido por las normas del Codice del consumo, aunque añade que, sin embargo "parece que se puede afirmar, en definitiva, que el art. 143 C. Cons. no representa por si mismo un obstáculo para una eventual puesta en marcha del poder del consumidor para convalidar, después del establecimiento de la relación, el contrato o las cláusulas que afecten a la nulidad relativa establecida en su favor; la inderogabilidad preventiva de la tutela acordada mediante esta solución no constituye por sí misma un índice seguro de una indisponibilidad absoluta, destinada a extenderse a las fases sucesivas de lo estipulado".

30 A. Barba, sub Art. 143, en V. Cuffaro, dir., Codice del consumo, Giuffrè, Milano, $3^{\mathrm{a}}$ ed., 837 (2012), que subraya: "esta característica de la tutela (indisponibilidad), la irrenunciabilidad de los derechos resulta independiente de la existencia de un pacto derogatorio y legitima al interesado para instar mecanismos de protección jurisprudenciales o administrativos cuando se hayan lesionado aquellas situaciones jurídicas subjetivas que le son reconocidas al consumidor y al usuario en cuanto que sujeto de 'procesos de adquisición y consumo' (art. 1) y no exclusivamente en cuanto parte de una específica relación de consumo. La irrenunciabilidad de los derechos es, por lo tanto, un principio regulador del mercado".

31 P. Perlingieri, In tema di tipicità e atipicità nei contratti, en Id., II diritto dei contratti fra persona 
las normas que se ocupan de garantizar la eficaz tutela del contratante débil, merece ser destacada la recogida en el D. Lg. de 20 de junio de 2005, n. 122, relativa a la protección de los adquirentes de inmuebles en construcción. Aquí, entre los diferentes instrumentos de protección el legislador ha regulado el caso que el constructor se encuentre en una situación de "crisis" 32 antes de la transmisión de la propiedad (o de otro derecho real de goce) del inmueble objeto del contrato, con el riesgo por el adquirente de perder el dinero ya pagado. Así el artículo 2 impone al constructor la obligación de consignar - antes o en el momento de la estipulación del contrato - una póliza de garantía, expedida por una entidad bancaria, una empresa aseguradora o un intermediario financiero autorizado para ello, que asegure la restitución de las sumas de dinero u otra eventual contraprestación que el constructor hubiera previamente recibido del adquirente o que, según los términos y lo establecido en dicho contrato, deba cobrar antes de la transmisión de la propiedad o de otro derecho real de goce.

La consigna de la garantía se establece como requisito de validez y no de eficacia del contrato; por ello su falta está sancionada con la nulidad del contrato, que expresamente según la disposición "solo puede hacer valer el adquirente".

Asimismo, nos podemos plantear si en este caso es apreciable de oficio la nulidad del contrato por la falta de constitución de la garantía. Algunos elementos nos llevarían a afirmar que queda excluida tal posibilidad ${ }^{33}$. En particular, se pone de relieve como: a) el silencio del legislador podría entenderse como la intención de no atribuir al juez esta facultad, puesto que en los casos en que ha querido introducirla lo ha hecho expresamente; por consiguiente, para los supuestos que quedan fuera del alcance del artículo $36 \mathrm{C}$. Cons. - debe entenderse como la norma que diseña el marco gene-

e mercato. Problemi dei diritto civile, cit., p. 400, observa como "emergen de forma siempre muy preponderante principios que exigen su aplicación no sólo en los contratos con consumidores, sino siempre que exista un contratante débil frente a un contratante fuerte o que haya una posición predominante, una falta de equilibrio, un reglamento injusto según nuestros principios y nuestros valores"; Id., II diritto civile nella legalitá costituzionale, óp. cit., 352 y ss.

32 Véase el art. 3.2 D. Lg. n. 122 del 2005 donde se precisa el sentido de la "situazione di crisi".

33 Sobre el fundamento constitucional de la disciplina del D. Lg. n. 122 del 2005 v. L. Mezzasoma, Il "consumatore" acquirente di immobili da costruire fra diritto al risparmio e diritto all'abitazione, óp. cit., 61 y ss.; Id., Il bene comune, il diritto all'abitazione e l'acquisto di immobili da costruire, en P. Grasselli (a cura di), Idee e metodi per il bene comune, Franco-Angeli, Milano, 234 y ss. (2009). 
ral relativo a las nulidades parciales encuadradas en el ámbito del consumo - parecería necesaria una expresa y análoga previsión; b) el interés del adquirente por no instar la nulidad podría colisionar con la obligación impuesta al juez de hacerlo de oficio; c) el requisito de que la apreciación de oficio debe operar en beneficio del contratante débil podría entrar en confrontación con el contenido de algunas disposiciones de Derecho Procesal (art. 100 C.P.C. o art. 183.4 C.P.C.); d) la apreciación de oficio se prestaría a peligrosas formas de abuso; e) en el caso en cuestión se apartaría de la propia lógica de la nulidad de origen comunitario, como demuestra el hecho de que la consecuencia del remedio no es la nulidad de una sola cláusula, sino del contrato íntegro; de estos argumentos resultaría que el derecho a la acción debería limitarse solo al adquirente, ya que los intereses sustentados en la nueva normativa, de relevancia constitucional, están destinados a conservar el vínculo y no a su ineficacia, a fin de alcanzar aquellos resultados previstos en la negociación.

Contra esta doctrina se puede observar que el interés defendido con el Decreto n. 122 del 2005 es de "orden público de protección" con perfiles de evidente relevancia constitucional. Así la posibilidad de apreciar de oficio la nulidad responde no a razones de tutela de los intereses supraindividuales conectados con el correcto funcionamiento del mercado (inmobiliario), sino a la necesidad de tutelar al adquirente considerado como persona y ciudadano. En este sentido se cita el artículo 47.2 de la Constitución italiana, donde expresamente se afirma el derecho a la propiedad de la vivienda como posible destino del ahorro popular ${ }^{34}$; y este artículo es solo un ejemplo de la necesidad más amplia de tutelar la dignidad de la persona y su concreta personalidad también en las relaciones económicas ${ }^{35}$. Por esta finalidad el legislador tiene que dictar normas que permitan disfrutar plenamente de un bien (en propiedad y en otras formas) ${ }^{36}$.

34 V., P. Perlingieri, Diritto all'abitazione, finanziamento all' impresa, alla cooperativa, alla persona, en G. Tatarano, (a cura di), Diritto all'abitazione, finanziamenti all'impresa, alla cooperazione, alla persona, Esi, Napoli, 1986, 324 y ss.

35 P. Perlingieri y M. Marinaro, Sub “Art. 47”, en P. Perlingieri, Commento alla Costituzione Italiana, Esi, Napoli, $2^{\text {a }}$ ed., 327 (2001).

36 Sobre el punto, v. por todos, E. Capobianco, "Profili costituzionali dell'accesso all'abitazione", en G. Tatarano, (a cura di), Diritto all'abitazione, finanziamenti all'impresa, alla cooperazione, alla persona, óp. cit., 257 y ss.; G. Tatarano, L'impresa cooperativa, in Tratt. dir. civ. e comm. 
Desde este punto de vista, la formulación utilizada en el artículo 2 del decreto de 2005, según el cual la "nulidad del contrato solo la puede hacer valer el adquirente" hay que interpretarla en el sentido de que se excluye la legitimación del constructor, pero no la del juez, con la precisión de que la intervención de la autoridad judicial está siempre subordinada a salvaguardar el interés del adquirente, de forma que no debe admitirse la actuación de oficio cuando un pronunciamiento favorable a la nulidad del contrato pudiera ser perjudicial para su intereses.

\section{LA NULIDAD EN LA CONTRATACIÓN TRAS LAS REFORMAS: HACIA UNA REGLAMENTACIÓN UNITARIA DE PROTECCIÓN DE LOS INTERESES DEL CONTRATANTE DÉBIL}

Al lado de estos supuestos, no podemos dejar de señalar que también en el ámbito de la disciplina de los contratos entre empresas se encuentran casos de nulidad que se configuran como remedio ligado no tanto a una carencia estructural del acto cuanto a aspectos de carácter reparador y sancionador de la tutela del contratante débil que, en estos casos, se identifica con el empresario que se encuentra en posición de inferioridad con respecto al empresario fuerte.

Hemos de hacer referencia a la nulidad contemplada en la normativa relativa a la subcontratación en la actividad productiva (Ley de 18 de junio de 1998, n. 192), donde se señala la necesidad de proteger al pequeño empresario que, operando en condiciones de absoluta dependencia de la contraparte, se expone al riesgo de unos pactos inicuos; y también a la nulidad regulada en el ámbito de la normativa sobre el retraso en los pagos de las transacciones comerciales (D. Lg., 231 del 9 de octubre de 2002), en la cual se tutela al acreedor en el caso de acuerdos sobre el pago gravemente injustos para él.

Estas menciones nos permiten destacar que el remedio de la nulidad de protección elaborada con base en las cláusulas abusivas en materia de tutela del consumidor, primero a nivel comunitario

Cicu e Messineo, III, 3, Giuffrè, Milano, 143 (2002); P. Perlingieri y M. Marinaro, Sub “Art. 45”, en P. Perlingieri, Commento alla Costituzione Italiana, óp. cit., 312 y ss. 
(Directiva n. 13 de 1993) y después recibida en el ordenamiento interno italiano (art. 36 C. Cons.), se ha afirmado progresivamente e impuesto como instrumento de tutela que actúa al margen de los límites subjetivos de aplicación de la normativa de consumo. $\mathrm{Y}$ esto se cohonesta con la tendencia que se está consolidando a nivel comunitario que progresivamente se orienta a la superación de toda la fragmentación de la normativa que está ligada a la calificación subjetiva de los contratantes, mediante la introducción de una regulación que resulte capaz de garantizar, más en general, una protección eficaz del contratante débil ${ }^{37}$.

En este sentido se ha desarrollado el planteamiento, sólidamente expuesto, según el cual mientras se asegure el mismo grado de tutela pueden y deben encontrar aplicación las nuevas reglas y los nuevos principios que "nacidos en salvaguarda de las exigencias impuestas por la tutela del consumidor, introducen en el sistema, considerado precisamente en su unidad, una más adecuada protección de los intereses. Protección que el intérprete terminará inevitablemente por utilizar también en los contratos de derecho común"38. Por otra parte, se puede observar, de un lado, que no existe una identidad absoluta entre consumidor y contratante débil ${ }^{39}$; $y$, de otro, que la exigencia

37 P. Perlingieri, Equilibrio normativo e principio di proporzionalità nei contratti, en Rass. dir. civ., 334 y ss. (2001); Id., In tema di tipicità ed atipicità nei contratti, en Id., Il diritto dei contratti fra persona e mercato, óp. cit., 391 y ss.

38 P. Perlingieri, Nuovi profili del contratto, óp. cit., 549, en Id., Il diritto dei contratti tra persona e mercato, óp. cit., 415 y ss. En la misma línea, con algunos matices, pueden verse también, G. Alpa, L'incidenza della nuova normativa sulle clausole vessatorie nei contratti dei consumatori sul diritto comune, en Riv. trim., 237 y ss. (1997); G. Benedetti, Il diritto comune dei contratti e degli atti unilaterali, Jovene, Napoli, 68 ss. (1997); E. Minervini, Tutela del consumatore e clausole vessatorie, Esi, Napoli, 56 y ss. (1999); P. Sirena, L'integrazione del diritto dei consumi nella disciplina generale del contratto, Riv. Dir. Civ., No. I, 787 y ss. (2004); Id., Il codice civile e il diritto dei consumatori, Nuova Giur. Civ. Comm., 277 y ss. (2005).

39 Algunas veces, en efecto, hay consumidores que no son los contratantes débiles, y en otras ocasiones hay contratantes débiles que no son consumidores. Sobre este tema, P. Perlingieri, La tutela del consumatore tra liberismo e solidarismo, óp. cit., subraya que el consumidor "no siempre es débil, ni siquiera económicamente. El ejemplo de la compra de órganos planteado por Stefano Rodotá debe hacernos reflexionar. Los consumidores de determinados bienes, si se unen, constituyen un grupo de presión fuerte y condicionante, como se ha dicho. Por otra parte, se puede ser protagonista del mercado como productores en un cierto sector y consumidores en otro: en ocasiones, el productor es consumidor y portador de handicaps culturales y psicofísicos, usuario de servicios organizados sin ánimo de lucro, de servicios públicos esenciales, consumidor en régimen de monopolio de hecho y otros. Son todas situaciones muy diversas". En esta misma línea, con algunas matizaciones, véanse P. Perlingieri, La tutela del contraente debole nelle negoziazioni immobiliari. Traccia per un possibile convegno, Rass. Dir. Civ., 746 y ss. (2000); Id., Relazione conclusiva, en M. Paradiso, (dir.), Imobili confini dell'autonomia privata, en Atti del Convegno di studi in onore del Prof. Carmelo Lazzara, Catania, 12-14 septiembre 2002, Giuffrè, Milano, 854 (2005). 
de garantizar el equilibrio contractual - que encuentra en materia de cláusulas abusivas la más importante expresión - se extiende también a las normativas especiales que regulan específicamente las relaciones entre empresarios. Así, de hecho, deben entenderse, por ejemplo: el concepto de "abuso" por parte de una o más empresas del "estado de dependencia económica" en el que se encuentra otra empresa con "excesivo desequilibrio de los derechos y las obligaciones", regulado en el caso de subcontratación industrial (art. 9 de la 1. n. 192 del 1998); o bien el concepto de "grave injusticia" en perjuicio del acreedor de los pactos "sobre la fecha del pago", al que se refiere el artículo 7 del D. Lg. de 9 de octubre de 2002, n. $231^{40}$.

Desde el punto de vista interpretativo, por tanto, trasladando progresivamente la atención del sujeto-contratante a la relación, resulta coherente con el sistema de jerarquía de fuentes y con los valores constitucionales una reconstrucción en términos unitarios de la figura del contrato, y al mismo tiempo de la disciplina del remedio de la nulidad como tutela de la parte débil del contrato ${ }^{41}$.

Importantes indicios en este sentido pueden apreciarse en las más recientes iniciativas promovidas a nivel comunitario, que vuelven a dar concreción al proceso de construcción del "derecho contractual europeo", o bien en la elaboración de una normativa que alcance el objetivo del acercamiento de las legislaciones, establecido con carácter general en el artículo 95 del Tratado de la Unión Europea ${ }^{42}$.

Recientemente, de hecho, con el "Libro verde" de $1^{\circ}$ de julio de $2010^{43}$, la Comisión Europea realiza una consulta pública para individualizar las posibles "estrategias para consolidar el mercado interno haciendo avanzar el sector del Derecho europeo de contratos" $\mathrm{y}$, a tal fin, propone analizar de modo unitario la posición de los

40 Para una referencia a estos aspectos, véase, F. Volpe, La giustizia contrattuale fra economia e mercato, Esi, Napoli, passim (2004).

41 En estos mismos términos, E. Minervini, Status delle parti e disciplina del contratto, en Obbl. contr., 11 y ss. (2008); Id., Il "terzo contratto", en Contratti, 499 y ss. (2009).

42 En clave histórica el proceso de construcción del derecho contractual europeo, es fundamental la referencia a la Comunicación de 11 de julio de 2001, Sobre el derecho contractual europeo, (сом(2001) 398 def.) G.U.C.E. L 255, de 13 de septiembre de 2001. Para un estudio más amplio, véase G. Alpa, La comunicazione n. 398/2001/CE sull'armonizzazione del diritto privato. Una premessa al dibattito, Nuova Giur. Civ. Comm., No. II, 425 y ss. (2001) donde se advierte sobre la necesidad de reflexionar sobre la oportunidad y sobre la modalidad a través de la cual podría llevarse a cabo "una acción comunitaria que incidiera en el sector del derecho contractual” y la Comunicación Mayor coherencia en el derecho contractual europeo: un plan de acción, del 12 de febrero de 2003 (сом(2003) 68 def.).

$43 \operatorname{Com}(2010) 348$ def. 
consumidores y las empresas, "especialmente aquellas pequeñas y medianas (PYME) con recursos limitados". El objetivo perseguido es asegurar un "desarrollo pleno del mercado interno, activando las transacciones transfronterizas, eliminando la diversidad de derechos nacionales de contratos [que] pueden comportar costos adicionales de las operaciones, ser fuente de inseguridad jurídica para las empresas y reducir la confianza de los consumidores en el mercado interno"; y que "además de eso provoca el riesgo de empujar a las empresas a adaptar las cláusulas contractuales" 44 .

Entre las materias que son objeto específico de intervención un lugar particularmente relevante viene reconocido a las cláusulas abusivas, consideradas como aquellas "disposiciones del derecho de contratos en general que valen para todos los contratos indistintamente". Ellas representan la base para la elaboración de una normativa que pretende una armonización plena y no mínima de las normativas existentes, capaz de asegurar la consecución del objetivo - expresado en el "Libro verde" de 2007 y confirmado en el "Libro verde" de 2010 - del "justo equilibrio entre un elevado nivel de tutela de los consumidores y la competitividad de las empresas" que sea tal que permita afirmar, en una comparación de todos los consumidores comunitarios "ya os encontréis en la UE ya hagáis adquisiciones partiendo de la UE no hay ninguna diferencia: vuestros derechos básicos son los mismos".

Así, se ha destacado que la existencia en varias directivas de cláusulas que hacen posible la introducción de varios niveles de protección en los Estados miembros (siempre que sea más elevado que los previstos en esas mismas directivas) desorienta a los consumidores y las empresas: los primeros, de hecho, se encuentran en una situación de inseguridad sobre el nivel de protección que les confieren los otros ordenamientos, lo que limita las adquisiciones en un Estado de la Unión Europea distinto del de procedencia; los segundos pueden encontrar obstáculos a la comercialización de sus productos y servicios, como consecuencia de las diversas reglas que pueden tener que respetar en el país donde intenten llevar a

\footnotetext{
44 En este sentido se puede entender la Propuesta de Reglamento sobra las ventas transfronterizas (сом(2011) 635 def.) que, aunque es un instrumento de regulación "opcional”, protegerá como contraente débil el consimidor y la PMI que negocian con empresas.
} 
cabo cierta operación comercial ${ }^{45}$. Estas consideraciones ponen en evidencia cómo la técnica legislativa hasta ahora utilizada por el legislador comunitario en el contexto del derecho de los consumidores no ha llevado a resultados convenientes para los sujetos involucrados en la relación de consumo y, al mismo tiempo, no ha favorecido la consolidación de un mercado común entre los distintos Estados miembros de la Unión.

Más en particular, se ha criticado el recurso al instrumento de la "directiva" mediante la cual se ha procedido a regular, una y otra vez, de manera directa una determinada modalidad contractual, regulando todos los singulares aspectos de la misma. El resultado que de ello ha derivado es la introducción de una disciplina inorgánica, que en su complejidad ofrece al intérprete un escenario normativo con perfiles muchas veces paradójicos, pudiéndose presentar "soluciones diferentes para situaciones análogas y soluciones idénticas para situaciones diferentes, con la consiguiente violación del principio de igualdad, fundamental también en el derecho comunitario"46. Se impone, por lo tanto, la necesidad de superar el status quo de la producción normativa, recurriendo a un instrumento normativo que permita superar los inconvenientes de la armonización mínima para alcanzar una armonización "máxima" de las distintas reglas.

En este contexto, parece conveniente la adopción de un reglamento comunitario que, fijando los principios de una efectiva armonización, pueda resolver todos los problemas derivados de la transposición de una o más directivas, tanto en lo que respecta al contenido como a los aspectos temporales ${ }^{47}$.

45 En esta perspectiva se pone también la Directiva de 14 de enero de 2009, Relativa a la protección de los consumidores con respecto a determinados aspectos de los contratos de aprovechamiento por turno de bienes de uso turístico, de adquisición de productos vacacionales de larga duración, de reventa y de intercambio contexto, donde en esta materia se afirma que " $A$ fin de reforzar la seguridad jurídica y poner plenamente a disposición de los consumidores y las empresas las ventajas que of rece el mercado interior, es necesario aproximar más las legislaciones pertinentes de los Estados miembros. Por lo tanto, es preciso armonizar totalmente determinados aspectos de la comercialización, venta y reventa de los productos vacacionales de larga duración y de los derechos de aprovechamiento por turno de bienes de uso turístico, así como el intercambio de estos últimos. No se debe permitir que los Estados miembros mantengan o introduzcan en su derecho interno disposiciones divergentes de las que recoge la presente directiva" (considerando n. 3).

46 P. Perlingieri, El derecho civil en la legalidad constitucional según el sistema italo-comunitario de las fuentes, óp. cit., 264.

47 P. Perlingieri, Relazione finale, Jornadas de Estudio "Il diritto dei consumi; realtà e prospettive", organizada por el Centro di Studi Giuridici sui diritti dei consumatori, Polo Scientifico Didattico di Terni - Università degli Studi di Perugia, Terni 30 de abril de 2008, ahora en La 


\section{CONCLUSión}

En conclusión, se ha intentado demostrar cómo el principio de autonomía contractual ha sido modificado para proteger al contrayente débil y cómo, en la persecución del este objetivo, se han cambiado dogmas y reglas tradicionales contenidos en el Código Civil.

tutela del consumatore tra normative di settore e codice del consumo, en G. Cavazzoni, L. Di nella, L. Mezzasoma \& V. Rizzo, (a cura di), Il diritto dei consumi, realtà e prospettive, óp. cit., 11 y ss. 


\section{REFERENCIAS}

\section{Libros}

A. Albanese, Violazione di norme imperative e nullità del contratto, Jovene, Napoli (2003).

A. Barba, Sub "Art. 143", en V. Cuffaro, dir., Codice del consumo, 3ª ed., Giuffrè, Milano (2012).

E. Capobianco, Diritto comunitario e trasformazioni del contratto, ESI, Napoli (2003).

E. Criscuolo, Diritto dei contratti e sensibilità dell'interprete, ESI, Napoli (2003).

E. Di Marzio, La nullità del contratto, Cedam, Padova (2008).

E. Graziuso, La tutela del consumatore contro le clausole abusive, Giuffrè, Milano (2010).

E. Greco, Profili del contratto del consumatore, Jovene, Napoli (2005).

F. Volpe, La giustizia contrattuale fra economia e mercato, ESI, Napoli (2004).

G. Benedetti, Il diritto comune dei contratti e degli atti unilaterali, Jovene, Napoli (1997).

G. Passagnoli, Nullità speciali, Giuffrè, Milano (1995).

G. Perlingieri, La convalida delle nullità di protezione e la sanatoria dei negozi giuridici, $2^{\mathrm{a}}$ ed., ESI, Napoli (2011).

I. Prisco, La nullità di protezione: indisponibilità dell'interesse e adeguatezza del rimedio, ESI, Napoli (2012).

L. Ferroni, La moderna concezione costituzionale e comunitaria di autonomia negoziale e la nuova filosofia cui si informa il regime delle invalidità, en Saggi di diritto civile, , 17 y ss., ESA, Pesaro-Urbino (2003).

L. Mezzasoma, Il "consumatore" acquirente di immobili da costruire fra diritto al risparmio e diritto all'abitazione, ESI, Napoli (2008).

P. M. Putti, La nullità parziale. Diritto interno e comunitario, ESI, Napoli (2004).

P. Perlingieri, El derecho civil en la legalidad constitucional según el sistema italocomunitario de las fuentes, $3^{\mathrm{a}}$ ed., Dykinson, Madrid (2008). Napoli (2003).

S. Polidori, Discipline delle nullità e interessi protetti, ESI, Napoli (2001).

S. Monticelli, Nullità, legittimazione relativa e rilevabilità d'ufficio, en Riv. dir. priv., 685 y ss. (2002).

S. Pagliantini, Autonomia privata e divieto di convalida del contratto nullo, Torino (2007).

V. Rizzo, "Trasparenza e "contratti del consumatore". La novella al codice civile, rist., ESI, Napoli (2002) 


\section{Contribuciones en obras colectivas}

A. Di Majo, La nullità, en M. Bessone, Trattato di diritto privato, XXVI, pp. 127 y ss., Giappichelli, Torino (2002).

E. Llamas Pombo, Ordinamento spagnolo e clausole vessatorie, en A. Bellelli, L. Mezzasoma \& F. Rizzo (a cura di), Le clausole vessatorie a vent'anni dalla direttiva CEE 93/13, pp. 89 y ss., ESI, Napoli (2013).

F. Rizzo (a cura di), Le clausole vessatorie a vent'anni dalla direttiva CEE 93/13, ESI, Napoli (2013).

S. Mezzacapo, Illiceità delle clausole “abusive” (tra presidi di 冈giustizia negoziale $e$ tutela amministrativa del "mercato"), en F. Capriglione (cur.), I contratti dei risparmiatori, pp. 142 y ss., Giuffré, Milano (2013).

S. Polidori, Nullità relativa e limiti alla disponibilità mediante convalida della tutela apprestata in favore del consumatore dal codice di settore, en G. Cavazzoni, L. Di Nella, L. Mezzasoma \& V. Rizzo (a cura di), Il diritto del consumi, realtà e prospettive, 212 y ss.

V. Rizzo, Art. 33, comma 1, en E. Cesáro, I contratti del consumatore, Commentario al Codice del consumo (D. Igs. 6 setiembre 2005 n. 206), Cedam, Padova (2007).

V. Rizzo, Codice del consumo e definizione di clausola vessatoria, en G. Cavazzoni, L. Di Nella, L. Mezzasoma \& V. Rizzo (a cura di), Il diritto del consumo, realtà e prospettive, p. 121, Esi, Napoli (2008).

\section{Artículos de revista}

A. Orestano, L'ineficacia delle clausole vessatorie: "contratti del consumatore" e condizioni generali, Riv. crit. dir. priv., 501 y ss. (1996).

A. Gentili, La "nullità di protezione", en Eur. dir. priv., spec. 77 y ss. (2011).

C. Caccavale, La nullità di protezione delle clausole abusive e l'art. 28 della legge notarile, en Notariato, 49 y ss. (2007).

C. Mignone, La disponibilità dell'azione di nullità nel sistema italo-comunitario delle patologie negoziali, en Corti umbre, 344 y ss. (2013).

D. Bonaccorsi Di Patti, Prime considerazioni sui procedimenti in materia di clausole vessatorie innanzi all'Autorità garante della Concorrenza e del Mercato, Dir. Fisc. Ass., 35 y ss. (2013).

E. Barale, La fideiussione obbligatoria, en Summa, No. 222, 70 (febrero de 2006).

E. Battelli, Il controllo amministrativo delle clausole inique, Eur. Dir. Priv., 1093 y ss. (2012).

E. Capobianco y G. Perlingieri (a cura di), Codice del consumo annotato con la dottrina e la giurisprudenza, Esi, Napoli (2009).

E. Di Marzio, Codice del consumo, nullità di protezione e contratti del consumatore, Riv. dir. priv., 844 (2005). 
E. Quadri, "Nullità" e tutela del "contraente debole”, Contr. impr.,1143 y ss. (2001).

F. Guaraccino, Inefficacia e nullità delle clausole vessatorie, Contr. impr./Eur., 618 y ss. (1997).

G. D'Amico, Diritto europeo dei contratti (del consumatore) e nullità virtuale (di protezione), en Contratti, 977 y ss. (2012).

--_-_-_-_, Nullità virtuale. Nullità di protezione (variazioni sulla nullità), en Contratti, 432 y ss. (2009).

G. Passagnoli, Note critiche in tema di sanabilità e rinunziabilità delle nullità di protezione, en 1 Persona e Mercato, 24 y ss. (2012).

G. Perlingieri, Sanatoria e responsabilità del notaio ex art. 28, l. 16 febbraio 1913, n. 89, en Corti umbre, 15 y ss. (2013).

G. Gioia, Nuove nullità relative e tutela del contraente debole, en Contr. impr., $1341 \mathrm{y}$ ss. (1999).

L. Valle, "L'inefficacia delle clausole vessatorie e il codice del consumo", IVI, 662 y ss. (2006).

, "L区inefficacia delle clausole vessatorie e le nullità a tutela della parte debole del contratto", en Contr. impr., 149 y ss. (2005).

M. Nuzzo, Art. 1469 quinqués. Ineficacia, Nuove leggi civ. comm., 1217 y ss. (1997).

P. Perlingieri, La nullità del contratto fra esigenze protettive e principio di conservazione, en Ann. Fac. econ. Bemvento, No. 9, 205 y ss. (2003).

P. Perlingieri, Nuovi profili del contratto, en Rass. dir. civ., 545 y ss. (2000).

S. Monticelli, Rilevabilità d'ufficio condizionata della nullità di protezione: il nuovo Atto della Corte di Giustizia, en Contratti, 1119 y ss. (2009).

S. Pagliantini, La nullità di protezione tra rilevabilità d'ufficio e convalida, en 1 Persona e Mercato, 20 y ss. (2009).

S. Polidori, Nullità relativa e potere di convalida, en Rass. dir. civ., 931 y ss. (2003).

V. Scalisi, Contratto e regolamento nel piano d'azione delle nullità di protezione, I IVI, 459 y ss. (2005).

--_-_-_--, Il diritto europeo dei rimedi: invalidità e inefficacia, I IVI, 843 y ss. (2007).

-, Invalidità e inefficacia. Modalità assiologiche della negoziabilità, en I Riv. dir. civ., 201 y ss. (2003).

, Nullità e inefficacia nel sistema europeo dei contratti, en Eur. dir. priv., 489 y ss. (2001). 
